\title{
Research
}

\section{Gender Patterns in Bird-related Recreation in the USA and UK}

\author{
$\underline{\text { Caren B. Cooper }}^{1}$ and Jennifer A. Smith ${ }^{2}$
}

\begin{abstract}
Recent studies show inter-related trends in both adult and youth populations in developed nations: a shift away from nature-based recreation, an overall decline in physical activity, and increasing obesity. For this study we examined gender patterns in a nature-based activity, observing wild birds, popular in two developed nations, the USA and UK. We collated data from several organizations and categorized data sources as representing activities that involve varying degrees of competitiveness and acting authoritatively. Patterns were consistent with the hypotheses that gender differences in preferred types of bird-related recreation reflected well documented gender-specific differences in preferences for competition and propensity to act authoritatively. Observing birds encompassed both a recreational hobby, "bird watching," that was female biased in the USA, and a competitive sport, "birding," that was heavily male biased among adults, but not youth, in both the USA and UK. Because of differences in gender participation in bird-related activities, fostering both competitive and noncompetitive bird-related activities is necessary to increase the likelihood of bringing larger segments of the population into nature-based recreation.
\end{abstract}

Key Words: birding; bird-watching; citizen science

\section{INTRODUCTION}

Recent studies show several notable trends in both adult and youth populations: a global decline in physical activity (WHO 2003), increasing obesity in the USA and UK (Rennie and Jebb 2005, Ogden et al. 2006), and a shift away from nature-based outdoor recreation, at least in the USA and Japan (Pergams and Zaradic 2008). Because these shifts may be linked to rising "videophilia", that is, the human tendency to focus on sedentary activities involving electronic media, then bringing segments of the population into nature-based recreation could help mitigate these inter-related trends (Zaradic and Pergams 2007). Nature-based recreation has additional mental health benefits, particularly for youth (Kuo and Taylor 2004) and females (Taylor et al. 2002). Also relevant to understanding trends in physical activity is that although the level of participation in recreational sports is fairly constant in the last decade, the type of participation, at least in the USA, has shifted from predominantly team sports to individual, less competitive sports (SGMA 2006). One approach to expanding participation in nature-based recreation is to reach underrepresented demographics. Thus, a starting point is to identify, and understand the basis of, current demographic patterns. Gender is frequently an important predictive influence on participation in sports and recreation (e.g., Matteo 1986, Koivula 1995, 2001, Moore et al. 2008). Nature-based recreation focused on birds is popular in the USA and UK, encompasses a wide array of activities, and attracts individuals with a diversity of skills, interests, preferences, motivations, backgrounds, and entry points (e.g., Bryan 1979). In this paper, our goal was to examine gender patterns within an assortment of bird hobbies in USA and UK to understand gender as one potential underlying source of the heterogeneity within this type of nature-based recreation.

In the USA and UK, observing wild birds has been a popular nature-based recreational activity for over 100 years, with millions participating. The historic popularity of observing wild birds is exemplified in organizations that encourage bird-related recreation and aid bird conservation such as the National Audubon Society formed in 1905 in the US and the British Trust for Ornithology (BTO) formed in 1932 in the UK. Currently, in the US, over 45 million people participate in bird-related recreational 
activities (USFWS et al. 2006). Just one of the many bird-related conservation organizations in the UK, the Royal Society for the Protection of Birds (RSPB), has an estimated membership of over one million (http://www.rspb.org.uk/phoenix/). Thus, a common way that people express their interest in bird-related recreation is by supporting organizations focused on wild birds.

Recreation related to observing wild birds includes diverse activities such as feeding birds, photographing birds, monitoring nests, creating bird-friendly habitat around residences, traveling to see birds, and creating lists of observed birds. For the purposes of this paper, we define the commonly used term 'bird watching' to encompass this very broad range of nonconsumptive hobbies (Kellert and Brown 1985, McFarlane 1994, Cole and Scott 1999). Some elements of bird watching involve making lists, such as lists of identified bird species, lists of places visited for bird watching, and, for those that monitor nests, lists of the total number of offspring fledged from monitored nests. The tallying of lists facilitates comparing the length of lists, from which manifests varying degrees of competitiveness within types of bird-related recreation.

'Birding' is a type of bird watching specifically focused on compiling lists of species identified either over a specified time period, e.g., day, weeks, year, life, or in a particular region, e.g., state, country (Donnelly 1981, 1994, Sheard 1999, Schaffner 2009). Birding is more likely to involve active searching for species not yet included on a life list and comparisons of lists with others. Birding requires slightly different skill sets, e.g., more often relying on auditory clues, and equipment than other types of recreational bird watching. Importantly, although bird watching is a leisure time hobby that provides emotional and aesthetic pleasure, individuals can participate in birding as a competitive sport because it has characteristics similar to mainstream sports (Donnelly 1981, 1994, Sheard 1999, Schaffner 2009). The goal of the sport of birding is to identify and list the greatest number of avian species (Scott et al. 1999). Like mainstream sports, birding sometimes becomes institutionalized, individuals or teams compete for victory, winners receive prizes, and competing can be physically demanding, e.g., competitive events that last 24 hours nonstop (Sheard 1999, Schaffner 2009).
Many factors influence the involvement and motivation of individuals in bird-related recreation (e.g., Kellert 1985, McFarlane 1994, Hvenegaard 2002, Moore et al. 2008). Generally, bird watchers and birders have stated motivations of seeing birds, being with friends, gaining the opportunity to experience nature and the outdoors, contributing to wildlife conservation, fascination with specialized equipment, and being able to escape from daily social responsibilities (Keller 1985, McFarlane 1994, Scott et al. 1999). However, across multiple demographics, gender is one of the most predictive influences on the attitudes, knowledge, and behaviors that are linked to the meanings people attach to the natural world, and toward animals, including wild birds (Kellert and Berry 1987).

Gender differences in perceptions and actions toward wildlife have theoretical and practical importance to wildlife professions, such as wildlife and recreation managers and ecologists. For example, Kellert and Berry (1987) utilized Gilligan's (1982) framework to understand gender differences in the meanings people attached to wildlife. Gilligan's paradigm examined the development of moral and cognitive differences between males and females. Gender differences arise through different socialization experiences, with females emphasizing interpersonal responsibility and caring for others and males emphasizing competition, assertiveness, and hierarchy (Gilligan 1982). In this paper, we are not addressing how gender differences might arise, but the potential consequences of gender differences on participation in bird-related recreation. We note that the importance of listing, and the subsequent competition it can facilitate, varies across the spectrum of bird-related recreational actions, from supporting bird organizations, to the hobby of bird watching, to the sport of birding, and to acting authoritatively by evaluating sightings or teaching skills. Consequently, we used gender studies in competition, confidence, and authority as a basis to develop our hypothesis.

Numerous psychological studies suggest that men are more competitive than women, with gender differences beginning in childhood, increasing through puberty, and continuing in adulthood (reviewed in Campbell 2002). Both theoretical and empirical evidence suggest that gender differences in preference for competition has a basis in different socialization of males and females, i.e., nurture 
(Ruble et al. 2006), and evolutionary history, i.e., nature (Daly and Wilson 1983, Campbell 2002, Van Vugt et al. 2007). Gender differences regarding competition, which are unrelated to actual performance (Niederle and Vesterlund 2007), are hypothesized to account for economic and career differences between men and women, with women underrepresented in competitive jobs (e.g., Gneezy and Rustichini 2004), and the stereotyping of sports as masculine (Koivula 1995). Recent work has shown that gender differences in entering competitions were related to the gender differences in overconfidence as well as basic gender preferences (Niederle and Vesterlund 2007). Males are more likely to be overconfident, i.e., rank themselves higher than their actual abilities relative to others, whereas females are more likely to be under confident, i.e., rank themselves lower than their actual abilities relative to others (e.g., Beyer 1990, Beyer and Bowden 1997). Gender differences in overconfidence are somewhat task-dependent, that is, more likely if the task is easy and/or perceived as being in the male domain (Lundeberg et al. 1994). Gender differences in confidence have been found in other studies of bird-related recreation. For example, in a survey of Carolina Bird Club members, males judged their bird identification skills higher than females, and $14 \%$ of females, compared to $<1 \%$ of males, opted to not rank themselves at all (Moore et al. 2008).

Within bird-related recreation, there are many activities that involve volunteering as part of coordinated schemes. Some of these schemes have hierarchies, relying on a few highly skilled volunteers to act in positions of authority. In workplaces, women are less likely to occupy positions of authority (Smith 2002). This pattern is consistent and robust at all spatial and temporal scales, i.e., state-level, national, global, historic, current, albeit with the least pronounced disparity in English-speaking countries (Wright et al. 1995, Smith 2002). However, even in countries with the least disparity among genders, gender remains a major impediment to attainment of authority (McGuire and Reskin 1993, Smith 2002). The reasons for the gender pattern in authority in the workplace have been examined from social, psychological, and historical perspectives (reviewed by Smith 2002). Females may have less training and experience, females may self-select out of positions of authority, or there may be a tendency for those in authority to act as gatekeepers and select individuals of similar gender for advancements through conscious or unconscious acts that control opportunities for mobility (Smith 2002). Alternatively, gender differences in overconfidence could influence preferences for acting in positions of authority. It is beyond the scope of this paper to review in detail the possible causes or which might be applicable to positions of authority in recreational activities. Here we ask whether common patterns of gender differences in competition, confidence, and authority translate into gender differences along the spectrum of birdrelated recreation.

We hypothesized that gender patterns in bird-related recreation reflect 1) the relationship between gender and competition, that is, fewer females participating in birding, and 2) the relationship between gender and authority, that is, fewer females acting authoritatively in birding. First, we categorized data sources by degree of competitiveness in the birdrelated activity and, based on the possible common link to confidence, culminated the competitiveness spectrum with data sources reflecting a high degree of authority, i.e., supportive, participatory, competitive, authoritative. We then tested the hypothesis by examining gender patterns across these categories in two developed countries where bird-related recreation is popular.

\section{METHODS}

We collated data from a variety of sources in the UK and USA to look for trends in gender demographics in bird-related recreation. We categorized data sources as Supportive, Participatory, Competitive, and Authoritative (Table 1). The Supportive category included sources of data on membership in bird conservation organizations. The Participatory category included data sources of enrollment in schemes that involve submitting bird observations to a centralized database for use by scientists, i.e., citizen science projects. The Competitive category included data sources of participation in events or organizations that evaluate the quantity of birds reported on lists. The Authoritative category included data sources of individuals with acknowledged experience and expertise in bird-related activities, and who often voluntarily help train and organize individuals, and/ or organize information from individuals, in the Participatory category. We viewed the categories of Supportive, Participatory, Competitive, and Authoritative as spanning a spectrum of no 
Table 1. Description of data sources on gender patterns in bird-related recreation projects divided into four groups based on the degree of competition (Supportive, Participatory, Competitive, and Authoritative).

Sources of Data Description

Supportive - Membership in the following organizations

CLO The Cornell Lab of Ornithology was founded in 1915 and its mission is to interpret and conserve the Earth's biological diversity through research, education, and citizen science focused on birds.

Audubon Audubon's mission is to conserve and restore natural ecosystems, focusing on birds, other wildlife, and Society their habitats for the benefit of humanity and the Earth's biological diversity.

RSPB The Royal Society for the Protection of Birds, which was founded in 1889, is a British charitable organization that promotes conservation and protection of birds, wildlife, and the environment through public awareness campaigns, petitions, and the operation of nature reserves in the UK.

BTO

The British Trust for Ornithology was established in 1933 as an independent, scientific research trust, investigating the populations, movements, and ecology of wild birds in the UK, with specialty in the design and implementation of volunteer wild bird surveys.

Participatory - Participation in the following citizen science projects

CUBs Celebrate Urban Birds is a year-round project to promote conservation in cities through gardening, the arts, and checklists of focal species based in the USA.

HFDS The House Finch Disease Survey works in conjunction with Project FeederWatch and relies on participants watching bird feeders to report the presence and absence of signs of avian conjunctivitis, which is visible as red swollen eyes.

NestWatch A nest-monitoring project that collects breeding data on all North American breeding birds.

Project

FeederWatch

CamClickr

BFL

CBC

EBird

Garden

Birdwatch

BBS (UK)

Nest Record

Scheme
A winter-long survey of birds that visits feeders anywhere in North America, and in which participants submit records every other week and pay a fee to join.

An online photo-tagging project to identify breeding behaviors in archived photos of nesting birds based in the USA.

Birds in Forested Landscapes is a breeding bird survey project focused on North American forest songbirds that uses audio playback to determine the presence or absence of breeding songbirds.

Christmas Bird Count is an annual winter count of birds across North America that began in 1900.

A year-round bird checklist project based in the USA.

A year-round survey of birds in UK gardens in which participants submit records weekly and pay a fee to join.

Breeding Bird Survey is grid-based survey of breeding birds in the UK.

A nest-monitoring project that gathers breeding data on birds in the UK.

Competitive - Membership and participation in the following listing organizations 
American

Birding

Association

UK400Club
A nonprofit organization that provides leadership to birders by increasing their knowledge, skills, and enjoyment of birding. Compile all record Birding Achievements, such as Year Lists, Day Lists, County Lists, etc.

A club within the British Birding Association to cater to the more discerning birder, and strives to maintain the Life Lists of the Top 900UK, top 500 Western Palearctic, and Top 1,000 World listing birders. Compile all record birding achievements, such as Year Lists, Day Lists, County Lists, etc,

Authoritative - Acknowledged authorities on birding

eBird state eBird flags records based on the values, or filter limits, set for each species in each regional filter. State reviewers reviewers assess these flagged records to make a determination on whether the record is valid.

CBC Regional Regional editors for the North American CBC compile data from CBC participants for their assigned Editors regions.

Birding Advice Recent book edited by White and Dunne (2007) providing advice from "North America's Top Birders." Book

Bird Ringing BTO bird ringing scheme trains and licenses participants to place identification rings on wild birds.

competitiveness to increasing competitiveness. Those in the Supportive category may not even carry out bird-related recreation, but presumably have past, if not current, experience or interest in birdrelated hobbies. There is nothing explicitly competitive about connecting to bird-related recreation through paying for membership in an organization. Those in the Participatory category may relate to bird-related recreation in a mildly competitive way, perhaps only in the sense that much of the participation involves keeping lists. The Competitive category includes individuals experiencing bird-related recreation in a competitive setting. The Authoritative category included data sources from schemes in which volunteers act authoritatively in their abilities and skills related to birds.

\section{Sources of data from the United States}

From the Cornell Lab of Ornithology (CLO; Table 1 ), we used the first names to determine gender of individuals who supported the CLO through membership in 2008 (Supportive, Table 1) and participants submitting bird observations to various citizen science projects in 2008 (Participatory, Table 1). The Audubon Society provided first names of participants in the Christmas Bird Count (Participatory, Table 1). For the Competitive category, we obtained data from the American
Birding Association List Report, which included individuals who have achieved checklists of sufficient length for a particular region, e.g., $80 \%$ of all possible species in an area, and opted to have their name published (ABA 2009; Table 1). Several citizen science projects have state or regional volunteers who review, edit, and proof bird lists. We used first names of reviewers of the Christmas Bird Count (CBC; http://www.audubon.org/bird/cbc/ regional/regional ed.html) and eBird (http://ebird.o rg/content/ebird/) to obtain data for the Authoritative category. We also used the first names of contributors to a recent edited book providing birding advice (White and Dunne 2007).

First names were assigned gender by using data from http://names.mongabay.com/male names $9 . \mathrm{htm}$ to obtain the 1,000 most common male, and 1,000 most common female names, ranked in order of prevalence. Seventy-nine names appeared on both male and female top 1000 lists. We designated gender of these unisex names in 23 cases where the name was ranked in the top 100 of one list and not in the top 100 of the other list, or if the name was in the top 200 of one list and not in the top 800 of the other list. Thus, gender was ambiguous and designated as unknown for 56 of the top 2,000 names. 


\section{Sources of data from the United Kingdom}

Data on Royal Society for the Protection of Birds (RSPB) and British Trust for Ornithology (BTO) members (Supportive, Table 1) were provided by these organizations with gender designated as male, female, or unknown. BTO information on the gender of members was based on a random sample of the membership as part of a market survey. Data on volunteers in BTO citizen science schemes (Participatory, Table 1) were provided by BTO with gender designations, except for Garden Birdwatch for which they provided titles of participants. We assigned gender based on titles as follows: males were designated from Lord, Monsieur, Mr., Reverend, and Sir; females from Lady, Miss, Misses, Mrs., Ms., and Sister; and all other titles, primarily military titles, were considered unknown gender. Couples were excluded as not applicable since they balance gender ratios.

The UK400 Club is an organization to which members submit bird lists and the top ranked members are awarded certificates. The UK400 Club ranks listing birders in several categories, including the top $900 \mathrm{UK}$, top 500 Western Palearctic, and top 10,000 World listing birders. Certification is also awarded for finding a rare species and for county and 24-hour day records (British Birding Association http://www.uk400clubonline.co.uk/). Data on UK400 Club members (Competitive, Table 1) were provided to the authors with gender designated as male or female.

One type of bird-related recreation that is federally regulated in the USA and UK involves humanely capturing birds and placing registered, unique bands or rings on their legs and then releasing them. This activity, termed banding in the USA and ringing in the UK, is commonly used by professional ornithologists to collect data regarding, for example, seasonal movements of birds. Volunteers often help with large-scale efforts to band/ring birds. In the USA, although individuals can find opportunities to band birds, they must do so under the supervision of professional ornithologists. Therefore, we did not include data sources on participation in bird banding in the USA because the overwhelming majority of registered banders are professionals not recreationists. However, in the UK, the number of individuals ringing as a form of bird-related recreation may be comparable to the numbers ringing as professional ornithologists. In the UK, there are different categories of permits for ringing, which reflect the level of experience: ' $T$ ' permits are awarded to beginners who are permitted to band in the presence of A- or C-permit holders; 'C' permits are awarded to those who demonstrate a high standard of ringing and several years of experience and they are allowed to band alone, but on behalf of an A-permit holder; ' $A$ ' permits are awarded to those who have had adequate training and are fully independent. Trainers are a subset of A-permit holders. We obtained data on the gender of ringers in each permit category from the BTO, but we could not distinguish those that ring for recreation from those that ring for professional purposes. We categorized banding/ ringing data sources into the Authoritative category because of the hierarchy within permits and because it requires much training.

\section{Statistical analyses}

We could not determine whether individuals appeared in multiple data sources, creating the potential for a lack of independence across data sources. For this reason, we do not pool data sources within categories but rather compare gender ratios within each data source.

For each data source, we calculated Pearson's chisquare goodness of fit statistic to test whether the observed number of males and females differed from expected. We computed the expected distribution based on a selected source population, namely the expected number of males and females based on the gender ratio of the general population in each country. In the USA and UK, the overall gender ratio of the population was 49M:51F (http:/ /www.statistics.gov.uk/census2001/demographic uk. asp; http://www.census.gov/).

In cases where we had some knowledge about the relationship between two data sources, we were able to calculate a second chi-square statistic using a narrower source population to generate the expected number of males and females. For example, we knew that many eBird participants were likely CLO members and so we compared the observed frequency of genders in eBird to expected frequencies based on gender frequencies of the US population, and to expected frequencies based on gender frequencies of CLO members. Similarly, we knew that all eBird state reviewers were eBird participants and so we tested the gender ratio of eBird state reviewers relative to the USA population and relative to eBird participants. We compared 
each chi-square statistic to the appropriate value in a chi-square table based on the degree of freedom to determine if the probability reveals a significant difference between observed and expected.

We analyzed the CBC in two ways, each based on a different assumption about potential bias. Within the $\mathrm{CBC}$, individuals were listed by count circle, that is, $24 \mathrm{~km}$-radius circle in which bird observations were recorded according to a protocol, and we could not track whether individuals participated in multiple count circles. Under the assumption that the frequency of participation in multiple count circles did not vary with the gender of the participant, we analyzed CBC data as one group. Under the assumption that the frequency of participation in multiple count circles did vary with the gender of participants, we analyzed the gender composition within count circles as well.

\section{RESULTS}

Our samples sizes were quite large for recreation projects in the Supportive category and gradually diminished with increasing competition and authority (Table 2). For each recreation project, we were able to assign gender to $90-99 \%$ of the individual names.

In both countries, the competitive activity of birding was heavily male biased as were activities that required expressions of authority. In the Supportive category, although the BTO was male biased, RSPB and CLO were slightly female biased (Table 3). Every Participatory scheme that was female biased did not involve birding (Table 3 ). We note that Celebrate Urban Birds (CUBs) and Project FeederWatch (PFW) both involve checklists, but the lengths of the checklists are limited by project design, e.g., focal species, or location, e.g., visiting feeders. Conversely, with the exception of Garden Birdwatch, every Participatory scheme of BTO was male biased and involved birding (Table 3). Garden Birdwatch is the only aspect of BTO that is predominantly female. All types of Competitive bird-related recreation were male biased (Table 3 ). All types of bird-related recreation in the Authoritative category were male biased.

The overall gender ratio of the $\mathrm{CBC}$ was $63 \mathrm{M}: 37 \mathrm{~F}$ (Table 3). Of the 2,237 count circles, $20.5 \%$ (436) were conducted by all male participants, $6.4 \%$ (142) by all female participants, and 74\% (1659) by both male and female participants. The circles with both male and female participants showed, on average, a similar male bias (62M:38F) as when we grouped the data.

Among ringers in the UK, the beginning level permit (T) was male biased, but only slightly. The male bias increased with the next level of permitting (C) and was $90 \mathrm{M}: 10 \mathrm{~F}$ in the highest level of permitting (A). Furthermore, trainers, who hold an A permit and are endorsed to teach ringing, also fit the Authoritative category, and are even more highly male biased (Table 4).

\section{DISCUSSION}

We documented striking gender differences across common types of bird-related recreation in the USA and UK. Patterns were consistent with the hypotheses that gender differences in likelihood of occupying positions of authority, and preference for competition, accounts for the over-representation of males, and under-representation of females, in birding.

Gender patterns reported in a variety of other studies have varied but we can now reconcile the differences by retrospectively looking at the amount of competitiveness in the categories of bird-related recreation each study evaluated. The studies that found male bias were those that examined competitive events, e.g., Great Texas Birding Classic (Scott et al. 1999), groups of more advanced bird watchers (e.g., 73\% male in Kellert 1985; 80\% male in Hvenegaard 2002), organizations that promote birding, e.g., 67\% male in the American Birding Association (Scott et al. 2005), or so called committed bird watchers (Kellert and Berry 1987). Conversely, studies that found a slight female bias examined casual bird watchers (Kellert and Berry 1987), and those that found no gender bias examined overall participation in the broadest spectrum of bird-related recreation (Burger 1997, USFWS et al. 2006). We note that the phrases "casual bird watching' and 'committed bird watching' as used by Kellert and Berry (1987) are analogous to bird watching and birding. Kellert and Berry (1987) distinguished casual from committed on the basis of at least 41 days participation and perceived ability to identify at least 40 bird species, but our results suggest that they probably could have been distinguished based on the extent of listing. Their 
Table 2. The sample size of males and females in each category decreased by an order of magnitude as the type of bird-related recreation becomes more competitive.

\begin{tabular}{lcccc}
\hline \hline & Total Male & & Total Female & Total \\
\cline { 2 - 2 } \cline { 4 - 4 } Supportive & 508,113 & & 587,233 & $1,095,346$ \\
Participatory & 45,312 & & 37,800 & 83,112 \\
Competitive & 6815 & 118 & 6933 \\
Authoritative & 230 & 26 & 256 \\
\hline
\end{tabular}

use of the terms casual and committed discounts the level of time commitment in much nonlisting birdrelated recreation, such as nest monitoring. Taken together these studies are consistent with our findings that females were more likely to be nonlisting bird watchers and males more likely to be listing birders.

Gender differences in hobbies and recreation are common; many studies find gender differences in participation in athletic sports (e.g., United States Commission on Civil Rights 1980), and consumptive uses of wildlife such as hunting and fishing (e.g., Kellert and Berry 1987). The different gender patterns that we found within bird-related recreation provide further evidence of the broad influence of gender patterns in competition, authority, and perhaps confidence, but other explanations for the patterns are possible.

The observed gender patterns may reflect a correlation with gender differences in constraints and/or other motivations. If we categorize the types of recreation according to location, i.e., home or away, then we find patterns of female participation in bird-related recreation around their residence and male participation away from their residence. For example, projects in which participants could conduct surveys from inside such as Project Feeder Watch, Garden Bird Watch, and Virtual Nest Watch, were female biased. Alternatively projects that observed birds away from their home often had male biased participation, such as Breeding Bird Survey and Birds in Forested Landscapes.

Females may have different motivations for birdrelated recreation than males. The patterns in the
Participatory category suggest that females may be motivated to help birds, teach children, or assist scientific endeavors, i.e., altruistic, whereas men may be more focused on achievement (Kellert 1985). Other studies have found that females were more likely to get involved in bird-related recreation through activities related to nest boxes or feeders (e.g., Moore et al. 2008). Although we cannot make reliable inferences regarding motivations of birders and bird watchers directly from our data, we may gain some insights by conceptualizing our results in the context of the recreation specialization framework (Bryan 1979, Decker etal. 1987). Within this framework, our results suggest that males are more likely to be achievement-oriented in their motivation, seeking to meet some standard of performance, whereas females might be more likely to be appreciation-motivated, participating to reduce stress or gain a sense of connection with nature. Interestingly, this pattern where birders, i.e., those with higher specialization, are achievementoriented and bird watchers, those with lower specialization, are appreciation-oriented, is counter to the direction of changes in motivations expected as individuals progress along the specialization continuum, i.e., high specialization has been hypothesized to lead to appreciation-oriented motivations (Bryan 1979, Decker et al. 1987).

Another alternative interpretation of the patterns we observed is that they are historic artifacts. Since bird-related recreation has a long history in the UK and USA, it is possible that current gender patterns in participation among adults reflect historic social norms more than current norms. To examine this, we found two sources of data on bird-related recreation among youth. In contrast to adult birders, 
Table 3. The percentage of males and females based on data sources of different bird-based recreation projects in the UK and USA. The chi-square statistics computed for each data source were greater than the critical value, $\mathrm{P}(\chi 2 \geq 3.841)=0.05$. Test 1 and Test 2 differ in the population used to compute the expected value, with Test 1 using the 49M:51F ratio of the general population and Test 2 using the gender ratio specific to the recreation project that is likely the source population for a particular project. $\dagger$ indicate recreation projects that involve listing. $\mathrm{N}$ is the number of individuals in each recreation project for which gender was known or assigned.

\begin{tabular}{llllllll}
\hline \hline $\begin{array}{l}\text { Degree of Competition or } \\
\text { Authority }\end{array}$ & Recreation Project & $\% \mathrm{M}$ & $\% \mathrm{~F}$ & $\begin{array}{c}\text { Test } 1 \\
\mathrm{X}^{2}\end{array}$ & $\begin{array}{c}\text { Test } 2 \\
\mathrm{X}^{2}\end{array}$ & (df, N) & Skew \\
\hline Supportive & & & & & & \\
& CLO members & 45 & 55 & 210 & N/A & $(1,32872)$ & F \\
& Audubon subscribers & 37 & 63 & 9548 & N/A & $(1,1657000)$ & F \\
& RSPB members & 48 & 52 & 354 & N/A & $(1,883774)$ & F \\
& BTO members & 60 & 40 & 629 & N/A & $(1,13000)$ & M
\end{tabular}

Participatory

\begin{tabular}{|c|c|c|c|c|c|c|}
\hline$\dagger$ CUB & 30 & 70 & 132 & 83 & $(1,912)$ & $\mathrm{F}$ \\
\hline HFDS & 36 & 64 & 134 & 65 & $(1,1982)$ & $\mathrm{F}$ \\
\hline NestWatch & 38 & 62 & 138 & 56 & $(1,2846)$ & $\mathrm{F}$ \\
\hline$†$ Project FeederWatch & 34 & 66 & 652 & 354 & $(1,7246)$ & $\mathrm{F}$ \\
\hline CamClickr & 33 & 67 & 167 & 95 & $(1,1626)$ & $\mathrm{F}$ \\
\hline$\dagger$ Breeding Bird Atlas & 62 & 38 & 239 & 412 & $(1,3529)$ & M \\
\hline BFL & 57 & 43 & 10 & 22 & $(1,371)$ & M \\
\hline$\dagger \mathrm{CBC}$ & 63 & 37 & 3023 & 11178 & $(1,38544)$ & M \\
\hline †eBird & 57 & 43 & 241 & 547 & $(1,9410)$ & M \\
\hline †Garden BirdWatch & 42 & 58 & 268 & 1843 & $(1,13649)$ & $\mathrm{F}$ \\
\hline$\dagger \mathrm{BBS}, \mathrm{UK}$ & 82 & 18 & 1001 & 463 & $(1,2296)$ & M \\
\hline Nest Record Scheme & 83 & 17 & 324 & 155 & $(1,701)$ & M \\
\hline$\dagger$ ABA List Report & 80 & 20 & 217 & 4199 & $(1,563)$ & M \\
\hline †UK400Club & 99.02 & 0.08 & 6562 & 92 & $(1,6416)$ & M \\
\hline †eBird state reviewers & 93 & 7 & 135 & 92 & $(1,174)$ & M \\
\hline $\begin{array}{l}\text { †CBC Regional } \\
\text { Editors }\end{array}$ & 93 & 7 & 33 & 17 & $(1,43)$ & M \\
\hline $\begin{array}{l}\text { †Recent Birding } \\
\text { Advice Book }\end{array}$ & 72 & 28 & 8 & N/A & $(1,39)$ & M \\
\hline
\end{tabular}


Table 4. The percentage of participants in the BTO Ringing Scheme by permit class. The chi-square statistics computed for each permit class were greater than the critical value at $\mathrm{P}=0.05$. Classes $\mathrm{AP}$ and $\mathrm{CP}$ are for those near retirement age in permit classes A and C, respectively (data on Trainers from Spence 2007).

\begin{tabular}{lccccccc}
\hline \hline Permit class & $\%$ Male & \%Female & $\mathrm{X}^{2}$ & $\mathrm{X}^{2}$ & $\mathrm{~N}$ & Unknown & Skew \\
\hline $\mathrm{A}$ & 90 & 10 & 478 & N/A & 711 & 0 & $\mathrm{M}$ \\
$\mathrm{AP}$ & 95 & 5 & 395 & N/A & 466 & 0 & $\mathrm{M}$ \\
$\mathrm{C}$ & 74 & 26 & 163 & N/A & 650 & 2 & $\mathrm{M}$ \\
$\mathrm{CP}$ & 87 & 13 & 70 & N/A & 121 & 0 & $\mathrm{M}$ \\
T & 58 & 42 & 19 & N/A & 571 & 2 & $\mathrm{M}$ \\
Total & 80 & 20 & 969 & N/A & 2519 & 4 & $\mathrm{M}$ \\
& & & & & & & $\mathrm{M}$ \\
Trainers & 95 & 5 & 316 & 10 & 373 & 0 & \\
\hline
\end{tabular}

bird-related recreation among youth, whether participatory or competitive, showed no statistical deviation from a 50M:50F gender ratio in the UK or US. In the UK, youth RSPB membership (Supportive) had a 50M:50F gender ratio ( $\mathrm{N}=98637$; data from RSPB). In the US, the winning teams in the World Series of Birding youth division (Competitive) had a gender ratio of $52 \mathrm{M}: 48 \mathrm{~F}$ ( $\mathrm{N}=25$; data from Cape May Bird Observatory). In addition, we obtained data on age categories of ringing participants and found that the gender ratio of ringers approaching retirement age were more highly skewed toward males for each permit category (Table 4). A longitudinal study is needed to determine whether gender patterns are in the process of changing with new societal norms or gender differences become established in adulthood.

\section{CONCLUSIONS}

Our findings have implications for efforts in reversing the declining trend in nature-based recreation. In order to leverage bird-related recreation to draw more people into connections with nature, fostering competitive and noncompetitive bird-related activities is necessary. Furthermore, birding is not just a recreational sport, but also an environmental sport akin to kayaking, hiking, and skiing (Schaffner 2009). Environmental sports have certain environmental requirements to make the sport possible, and enjoyment of the sport is partly because of the quality of the natural environment. Bird-related recreation has economic and ecological importance, with potential to generate funding and awareness for wildlife conservation (e.g., Hvenegaard et al. 1989, U.S. Fish and Wildlife Service and U.S. Census Bureau 2003, as cited in Sali et al. 2008). Bird-related recreation has direct effects on wildlife/recreation management decisions and indirect effects on ornithological research and conservation via citizen science participation.

Our sample sizes for each category varied greatly, with numbers decreasing by roughly an order of magnitude from Supportive, Participatory, Competitive, and Authoritative categories (Table 2). Of those that participate in bird-related recreation, only a small percent have been reported to keep life lists (5\% according to the USFWS et al. 2006 survey). Our samples are not random samples of the UK and USA populations, but they may roughly reflect the variation in various types of bird-related recreation. Even though competitive birding may currently involve fewer individuals, competitive activities may be more visible to the public as they are often fund-raisers promoted by conservation organizations (Scott et al. 1999). If competitive birding involves only an elite group from the pool of bird-related 
recreationists, then increasing competitive birding opportunities may be an effective strategy to increase the numbers involved overall in birdrelated recreation.

Our findings suggest a future research priority should be to understand modes of entry into birdrelated recreation as well as progression to different forms of bird recreation. Entry and progress is particularly relevant given the gender patterns in the Authoritative category. In other arenas with gender imbalance, gender differences in positions of authority do not only indicate gender inequity, but are likely to be a significant cause of inequality (Wright et al. 1995, Smith 2002). In other words, gender inequity can influence entry and progression and thus perpetuate gender inequity. Thus, current gender patterns in authoritative forms of birdrecreation could have important implications if the activities from which those data sources arose were entry points, or pivotal points of progression, in bird-related recreation.

Future research should aim at understanding gender differences in bird-related recreation and determining motivations and constraints. Such an understanding would be useful to develop schemes or events to draw broad segments of the population into bird-related recreation. For example, by adding an aspect of discrete competitiveness into volunteer based scientific surveys, i.e., citizen science, male participation may increase and, subsequently, this will increase the overall number of citizens contributing to ecological studies. Research is needed to explore the potential caveat as to whether adding a competitive element could lead to biased data. If gender patterns in competition are linked to confidence, then visual and auditory field guides could help counter gender differences in confidence and draw more female participants to birding organizations. If gender patterns in bird-related recreation are historic artifacts, then future efforts should address ways to target younger age groups, perhaps by bringing bird-related activities to schools and youth clubs. Furthermore, such encouragement may help reduce the increasing problems of obesity and inactivity among children and promote active lifestyles within the family. Finally, because birding and ringing are a skill frequently used in the profession of ornithology, and a recreation activity upon which professional networking may take place, e.g., professional societies offer birding trips during annual conferences, future research is also needed to examine the potential relationship between these types of bird-related recreation and entrance, advancement, and achievement in ornithology.

Responses to this article can be read online at: http://www.ecologyandsociety.org/voll5/iss4/art4/responses/

\section{Acknowledgments:}

We thank A. Duncan, K. Dale, L. G. R. Evans, T. Evans, M. Grantham, D. Leech, and L. Santiago for help accessing data. We thank D. Ardia, T. Phillips, K. Purcell, M. C. Schmink, J. Shirk, E. Van Etten, $M$. Voss, and three anonymous reviewers for comments that improved this manuscript.

\section{LITERATURE CITED}

American Birding Association (ABA). 2009. 2008 ABA Big Day Report \& ABA List Report. American Birding Association, Colorado Springs, Colorado, USA.

Beyer, S. 1990. Gender differences in the accuracy of self-evaluations of performance. Journal of Personality and Social Psychology LIX:960-970.

Beyer, S., and E. M. Bowden. 1997. Gender differences in self-perceptions: convergent evidence from three measures of accuracy and bias. Personality and Social Psychology Bulletin XXIII:157-172.

Bryan, H. 1979. Conflict in the great outdoors. Birmingham Publishing, Birmingham, Alabama, USA.

Burger, J. 1997. Recreation and risk: potential exposure. Journal of Toxicology and Environmental Health 52:269-284.

Campbell, A. 2002. A mind of her own: the evolutionary psychology of women. Oxford University Press, Oxford, UK.

Cole, J. S., and D. Scott. 1999. Segmenting participation in wildlife watching: a comparison of casual wildlife watchers and serious birders. Human Dimensions of Wildlife 4:44-61. Doi: 10.1080/108- 
71209909359164

Daly, M., and M. Wilson. 1983. Sex, evolution, and behavior. Second edition. Wadsworth Publishing, Belmont, California, USA.

Decker, D. J., T. L. Brown, B. L. Driver, and P. J. Brown. 1987. Theoretical developments in assessing social values of wildlife: toward a comprehensive understanding of wildlife recreation involvement. Pages 76-95 in D. J. Decker, and G. R. Goff, editors. Valuing wildlife: economic and social perspectives. Westview Press, Boulder, Colorado, USA.

Donnelly, P. 1981. On verification: a comparison of climbers and birders. Pages 484-499 in Career patterns and career contingencies in sport. Proceedings of the First Regional Symposium of the International Committee for the Sociology of Sport. University of British Columbia, Vancouver, British Columbia, Canada.

Donnelly, P. 1994. Take my word for it: trust in the context of birding and mountaineering. Qualitative Sociology 17:215-241.

Gilligan, C. 1982. In a different voice: psychological theory and women's development. Harvard University Press, Cambridge, Massachusetts, USA.

Gneezy, U., and A. Rustichini. 2004. Gender and competition at a young age. American Economic Review 94:377-381.

Hvenegaard, G. T. 2002. Birder specialization differences in conservation involvement, demographics, and motivations. Human Dimension of Wildlife 7:21-36.

Hvenegaard, G. T., J. R. Butler, and D. K. Krystofiak. 1989. Economic values of bird watching at Point Pelee National Park Canada. Wildlife Society Bulletin 17:526-531.

Kellert, S. R. 1985. Birdwatching in American society. Leisure Sciences 7:343-360.

Kellert, S. R., and J. K. Berry. 1987. Attitudes, knowledge and behaviors toward wildlife as affected by gender. Wildlife Society Bulletin 15:363-371.
Kellert, S. R., and P. J. Brown. 1985. Human dimensions information in wildlife management, policy and planning. Leisure Science 7:269-280.

Koivula, N. 1995. Ratings of gender appropriateness of sports participation: effects of gender-based schematic processing. Sex Roles 33:543-557.

Koivula, N. 2001. Perceived characteristics of sports categorized as gender-neutral, feminine and masculine. Journal of Sport Behavior 24:377-393.

Kuo, F. E., and A. F. Taylor. 2004. A potential natural treatment for attention-deficit/hyperactivity disorder: evidence from a national study. American Journal of Public Health 94:1580-1586.

Lundeberg, M. A., P. W. Fox, and J. Puncochar. 1994. Highly confident but wrong: gender differences and similarities in confidence judgments. Journal of Educational Psychology 86 (1):114-121.

Matteo, S. 1986. The effect of sex and genderschematic processing on sports participation. Sex Roles 15:417-432.

McGuire, G., and B. Reskin. 1993. Authority hierarchies at work: the impact of race and sex. Gender and Society 7:487-506.

McFarlane, B. L. 1994. Specialization and motivations of birdwatchers. Wildlife Society Bulletin 22:361-370.

Moore, R. L., D. Scott, and A. Moore. 2008. Gender-based differences in birdwatchers' participation and commitment. Human Dimensions of Wildlife 13:89-101.

Niederle, M., and L. Vesterlund. 2007. Do women shy away from competition? Do men compete too much? Quarterly Journal of Economics

CXXII:1067-1087.

Ogden, C. L., M. D. Carroll, L. R. Curtin, M. A. McDowell, C. J. Tabak, and K. M. Flegal. 2006. Prevalence of overweight and obesity in the United States, 199-2004. Journal of the American Medical Association 295:1549-1555.

Pergams, O. R. W., and P. A. Zaradic. 2008. Evidence for a fundamental and pervasive shift from nature-based recreation. Proceedings of the 
National Academy of Science 107(7):2295-2300.

[online] URL: http://www.pnas.org/cgi/doi/10.1073/ pnas.0709893105.

Rennie, K. L., and S. A. Jebb. 2005. Prevalence of obesity in Great Britain. Obesity Review 6:11-12.

Ruble, D. N., C. L. Martin, and S. A. Berenbaum. 2006. Gender development. Pages 858-932 in W. Damon, and R. M. Lerner, editors. Handbook of child psychology. Sixth edition. Wiley, New York, New York, USA.

Sali, M. J., D. M. Kuehn, and L. Zhang. 2008. Motivations for male and female birdwatchers in New York State. Human Dimensions of Wildlife 13:187-200.

Schaffner, S. 2009. Environmental sporting: birding at Superfund sites, landfills, and sewage ponds. Journal of Sport and Social Issues 33:206-229.

Scott, D., S. M. Baker, and C. Kim. 1999. Motivations and commitments among participants in the Great Texas Birding Classic. Human Dimensions of Wildlife 4:50-67.

Scott, D., R. B. Ditton, J. R. Stoll, and T. L. Eubanks, Jr. 2005. Measuring specialization among birders: utility of a self-classification measure. Human Dimensions of Wildlife 10:53-74.

Sheard, K. 1999. A twitch in time saves nine: birdwatching, sport, and civilizing processes. Sociology of Sport Journal 16:181-205.

Smith, R. 2002. Race, gender, and authority in the workplace: theory and research. Annual Review of Sociology 28:509-542.

Spence, I. M. 2007. The age structure of the ringing scheme, revisited. Ringers Bulletin 12:25.

Sporting Goods Manufacturers Association (SGMA). 2006. Sports participation, topline report, 2006 edition. SGMA, Washington, DC, USA.

Taylor, A. F., F. E. Kuo, and W. C. Sullivan. 2002. Views of nature and self-discipline: evidence from inner city children. Journal of Environmental Psychology 22:49-63.
United States Commission on Civil Rights. 1980. More hurdles to clear: women and girls in competitive athletics. Clearinghouse Publication, Number 63, Washington, D.C., USA.

United States Fish and Wildlife Service (USFWS), and U.S. Department of Commerce, U.S. Census Bureau. 2006. National survey of fishing, hunting and wildlife-associated recreation. Government Printing Office, Washington, D.C., USA.

Van Vugt, M., D. De Cremer, D. P. Janssen. 2007. Gender differences in cooperation and competition: the male-warrior hypothesis. Psychological Science 18:19-23.

White, L., and P. Dunne, editors. 2007. Good birders don't wear white: 50 tips from North America's top birders. Houghton Mifflin, New York, New York, USA.

World Health Organization (WHO). 2003. Health and development through physical activity and sport. WHO/NMH/NPH/PAH/03.2. WHO Document Production Services, Geneva, Switzerland. [online] URL: http://whqlibdoc.who.int/hq/2003/W HO NMH NPH PAH 03.2.pdf.

Wright, E., J. Baxter, and G. E. Birkelund. 1995. The gender gap in workplace authority: a crossnational study. American Sociological Review 60:407-435.

Zaradic, P. A., and O. R. W. Pergams. 2007. Videophilia: implications for childhood development and conservation. Journal of Developmental Processes 2:130-144. 